\title{
Deployment of Professional Librarians: A Barrier to the Availability of Publications in a Developing Country
}

\section{Georgiana K. N. Nwagha}

\section{INTRODUCTION}

The primary aim of librarians and information scientists is to serve users by providing them with access to recorded information. To accomplish this aim there are two requirements: the first is to help users recognize which records may be of interest and, secondly, to make it possible for the user to have access to these records.

It is obvious, therefore, that universal bibliographic control (UBC), whose primary aim is to aid users in the discovery of what records of interest exist, is not enough in itself. In fact, it has been argued that it is no use providing an ever fuller and faster supply of references if the documents to which they referred cannot be obtained. ${ }^{1}$ To satisfy users, publications themselves must also be accessible to anyone. It has thus been realised, both by international bodies, such as IFLA and UNESCO, and by individual countries, that to derive the full benefit of the efforts towards UBC, there must be a programme of universal availability of publications (UAP). ${ }^{2}$

The present exponential growth of publications and the ever-increasing cost of printed materials mean that not even libraries in the most highly developed countries can hope to satisfy all the information needs of its users. As a result, resource sharing among libraries is increasingly being accepted as the only realistic means of maximizing the availability of materials and services needed for scholarly research. Unfortunately, in the developing countries, where the inadequacy of individual libraries is felt more acutely, certain barriers decrease the availability of publications, and resource sharing among libraries cannot be relied upon to maximize the availability of documents. Several of these barriers have been identified in the literature ${ }^{3,4}$ and need not be elaborated here. They include shortage of funds, insufficient and unsatisfactory photocopying machinery, poor postal systems, shortage of foreign exchange, and inadequate union lists. However, there is one factor that has hitherto not been clearly identified, nor even realised as a barrier to the availability of publications in some developing countries. This is the deployment of professional librarians in libraries, which is quite distinct from the lack of a sufficient number of trained librarians. Deployment means the actual jobs performed by the available professional librarians. These jobs can vary from administrative duties, acquisitions and technical services such as cataloging and classification, to reference and readers' services. The degree to which users' needs are served depends on which of these duties are performed by professional librarians. This paper will in fact demonstrate that the performance of reference services in a research library in $\mathrm{Ni}$ geria by a professional librarian does affect the level of availability of publications to users.

\section{METHODS}

A survey of eighteen agricultural research institute libraries in Nigeria was carried out by means of a self-completed questionnaire. Sixteen of these institutes were established and financed by the federal government of Nigeria to promote agricultural research and production. One is an international institute for tropical agri- 
cultural research, while the eighteenth is the Faculty of Agriculture of the University of Nigeria. The institutes were chosen to ensure an even coverage of the different geographic regions of the country.

Each of the institute libraries was sent multiple copies of the questionnaire, and library personnel at the reference desk were requested to fill out one copy each time a research scientist made a demand for a publication during a period of six months. The aim was to enable the libraries to keep a record of the sources used in satisfying demands (whether from local stock or from another library), the satisfaction time (measured in hours or days), and the reasons for failure in cases where the demands were not satisfied. The questionnaire also requested that the rank of the reference personnel be stated; that is, whether the reference personnel was a professional librarian or a nonprofessional member of the staff.

After two or three reminders, fourteen of the eighteen libraries returned the completed questionnaires at the end of the recording period and a total of 506 forms were received. The questionnaires were coded and analysed by means of the Statistical Package for the Social Sciences (SPSS).

\section{RESULTS}

The initial analysis showed that only three out of the fourteen libraries had a professional reference librarian involved in completing the questionnaire. In the other eleven libraries, nonprofessional library personnel carried out the reference functions. It was further discovered that in the first group of libraries (that is, those with professional reference librarians), 85 percent of the demands made by the re- search scientists were satisfied, whereas 95 percent of the demands were satisfied in the second group of libraries (see table 1 ). These results would tend to indicate that the research libraries with nonprofessional reference personnel had a higher availability level than those with professional reference librarians.

However, further analysis of the data indicates that this was not the true state of affairs. Table 2 demonstrates that 99.2 percent of the demands made at the libraries without professional reference staff were satisfied immediately from the local stock of the libraries. On the other hand, only 67.5 percent of the demands were satisfied from the local stock of the group of libraries with professional reference staff. Also, while the latter group of libraries satisfied 32.5 percent of the demands made with materials obtained from other libraries, it was revealed that little interlibrary borrowing was done by the group of libraries without professional reference librarians.

There are two possible explanations for this situation. Either the second group of libraries did not engage in interlending because the nonprofessional reference personnel could not for some reason initiate interlibrary loan requests, or the researchers using these libraries did not request materials that were not available in the libraries. Considering that Nigeria is a developing country, it is not likely that these libraries are self-sufficient and could satisfy all the demands of the researchers, as indicated by the data. Rather, it was suspected that researchers using libraries whose personnel were nonprofessional were consciously suppressing some of their document needs because of a preconceived knowledge of the capabilities of

TABLE 1

PROPORTION OF SATISFIED DEMANDS

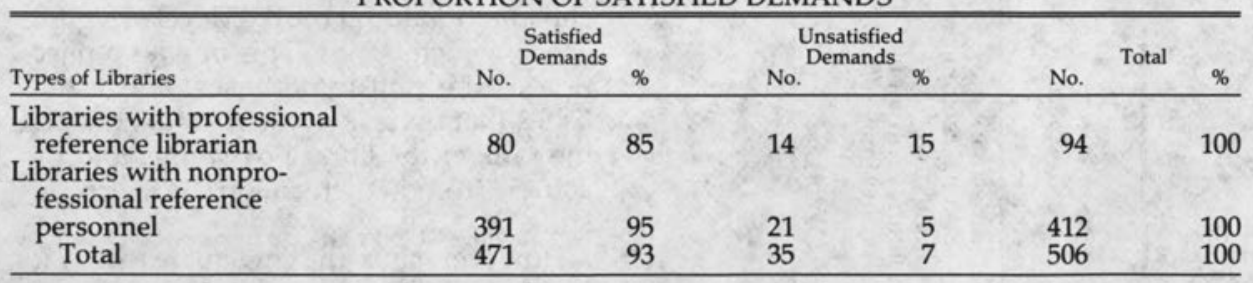




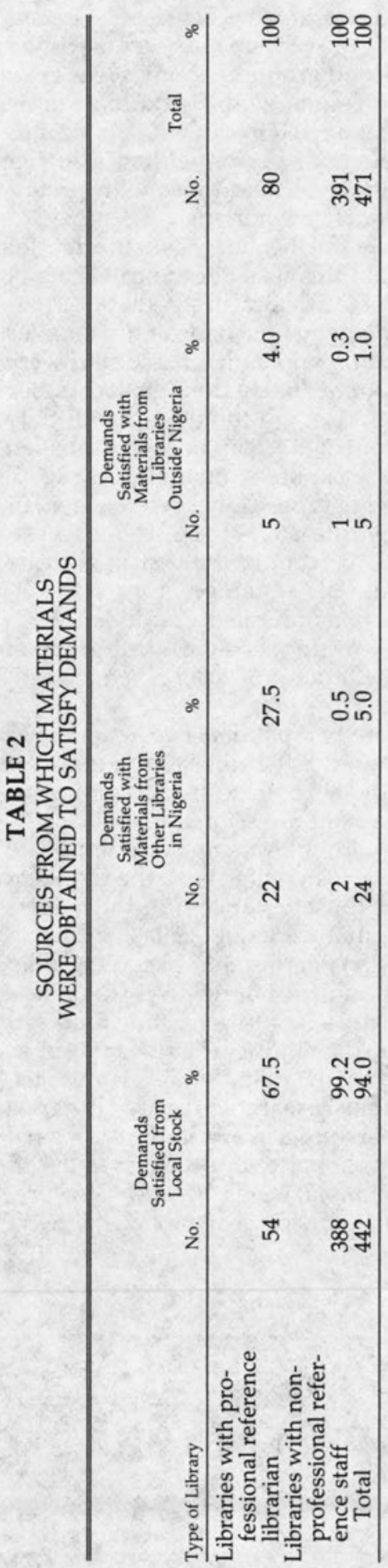

the library personnel serving them. Consequently, it was decided to test whether the rank of the reference personnel in the libraries surveyed had an effect on the information-seeking behaviour of the research scientists.

To do this, the actual demands made by the agricultural research scientists at the different institute libraries were categorized into two types of questions: simple locational questions and complex reference questions. This categorization was based on that of K. Emerson, who had categorized reference transactions into two main groups-directional questions and reference questions. ${ }^{5}$ On the basis of this categorization, demands that were satisfied immediately, simply by locating materials on the shelves of the libraries concerned, were classed in the first category as simple or quick-reference questions. The other demands, satisfied after several days with materials from sources outside the library stock, were placed in the second category as complex reference transactions. The following two null hypotheses were then tested for their acceptance or rejection:

- There is no relationship between the rank or qualification of the library personnel manning the reference desk of a research library and the source from which materials are obtained to satisfy demands made.

- There is no relationship between the rank or qualification of the library personnel manning the reference desk of a research library and the type of questions asked by research scientists.

The two hypotheses were tested by carrying out a chi-square test of statistical significance between the two variables in each case, again using SPSS. Table 3 shows that the chi-square value for the first test is 119.56 , with one degree of freedom. This is much greater than the critical chi-square value at the 0.05 level of significance, which is 3.84 . This implies a rejection of the null hypotheses, and establishes that there is a relationship between the rank of the library personnel and the source from which materials were obtained.

However, since the chi-square test by it- 
self could only indicate that the variables tested are related, it was found necessary to carry out two further analyses to assess the strength of the relationship between the two variables. The phi coefficient, which is specifically for $2 \times 2$ table, was found suitable, as it makes a correction for the fact that the value of the chi-square is directly proportional to the number of cases, by adjusting the $X$ value. Both the phi value of 0.50 and the contingency coefficient value of 0.45 indicate that there is a fairly strong association between the two variables.

Table 4 shows that the chi-square value for the second test is 229.52, with one degree of freedom. This value is again much greater than the critical value of 3.84 at
0.05 level of significance. The null hypothesis could therefore be rejected and there is an indication that a relationship exists between the rank of the library personnel and the type of questions asked by research scientists. As in the case of the first hypothesis, both the phi and contingency coefficient tests for statistical significance were carried out to measure the strength of the association between the variables. The values of phi (which is 0.67 ) and the contingency coefficient (which is 0.55 ) both establish that there is indeed a strong relationship between the two variables.

\section{CONCLUSION}

The results of the above two tests have confirmed the suspicion that the agricul-

TABLE 3

CROSS-TABULATION OF RANK OF REFERENCE STAFF BY SOURCE OF DOCUMENT

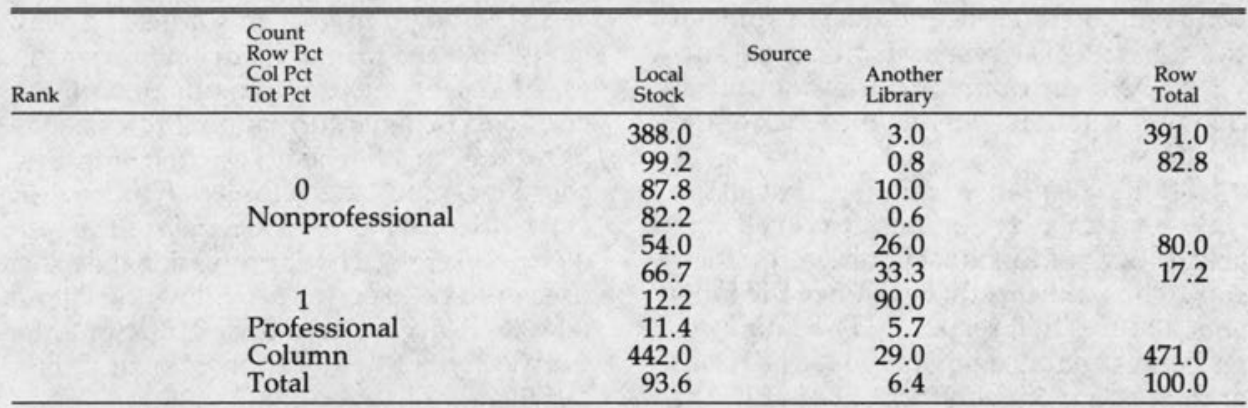

Raw chi-square $=119.56$ with one degree of freedom

$\mathrm{Phi}=0.50330$

Contingency coefficient $=0.44957$

TABLE 4

CROSS-TABULATION OF RANK OF REFERENCE STAFF BY TYPE OF QUESTION

\begin{tabular}{|c|c|c|c|c|}
\hline Rank & $\begin{array}{l}\text { Count } \\
\text { Row Pct } \\
\text { Col Pct } \\
\text { Tot Pct }\end{array}$ & $\begin{array}{l}\text { Simple } \\
\text { Question }\end{array}$ & $\begin{array}{l}\text { Complex } \\
\text { Question }\end{array}$ & Row Total \\
\hline & $\begin{array}{l}0 \\
\text { Nonprofessional } \\
1 \\
1 \\
\text { Professional } \\
\text { Column } \\
\text { Total }\end{array}$ & $\begin{array}{r}379.0 \\
92.0 \\
95.0 \\
74.9 \\
20.0 \\
21.3 \\
5.0 \\
4.0 \\
399.0 \\
78.9\end{array}$ & $\begin{array}{r}33.0 \\
8.0 \\
30.8 \\
6.5 \\
74.0 \\
78.7 \\
69.2 \\
14.6 \\
107.0 \\
21.4\end{array}$ & $\begin{array}{r}412.0 \\
81.4 \\
\\
94.0 \\
18.6 \\
\\
506.0 \\
100.0\end{array}$ \\
\hline
\end{tabular}

Raw chi-square $=229.52$ with one degree of freedom

Phi $=0.6735$

Contingency coefficient $=0.55862$ 
tural research scientists using those libraries manned by nonprofessional reference personnel were consciously suppressing some of their demands for documents. Were demands for materials outside the libraries' stock being suppressed because the researchers did not have confidence in the library personnel's ability to obtain such materials for them, or was it because of the poor success rate of such demands in the past? The answers to these questions can be established only through further research into the motives behind the information-seeking behaviour of the research scientists and into the reasons for present decisions in the deployment of librarians. This would require the adoption of qualitative research methods such as less formally structured interviews and free-flowing discussions. However, it may be concluded that the presence of nonprofessional library personnel in the reference context of some of the agricultural research libraries surveyed has contributed to the nonutilization of documents outside the stock of the libraries.

It should be pointed out here that all the eighteen research libraries surveyed had at least two professional librarians on their staff. Thus, the fact that eleven of the fourteen libraries that responded had nonprofessional reference personnel was a result of the internal deployment of staff in the respective libraries and not because of a total absence of professional librarians. Presumably, the professional librarians in these libraries were deployed in other service areas, such as administration, acquisition, or technical services, where their expertise was felt to be most needed.

This situation would tend to lead one to agree with Wilkinson and Miller that "at times, indeed, the field's pre-occupation with the internal mechanisms of library operation appears to have been little less than disfunctional in terms of the library's role in society. Expertise in selection, in processing and in administration are recognized by the initiated as being essential to effective library operation. To the public, however, recognition is given only to the end product-the ability of the library's staff to negotiate satisfactorily, a physical or intellectual translation of information that meets the user's needs."

At the beginning of this article, it was stated that the primary aim of librarians is to serve users by providing them with access to recorded information. Professional librarians in Nigerian research libraries could make positive efforts to achieve this aim by deploying professional staff in reference services. Thus, professional expertise could be used for providing the clientele with access to needed documents irrespective of the location of such publications.

\section{REFERENCES}

1. D. J. Urquhart, "UAP: What Can We Do About It?" IFLA Journal 4:338-42 (1978)

2. International Federation of Library Associations, "Medium Term Programme" (The Hague: IFLA, 1976).

3. M. B. Line, "Planning Interlending Systems for Developing Countries: A Summary and Response," Interlending Review 9:93-97 (1981).

4. G. K. N. Nwagha, "Barriers to the Availability of Scientific Journals in Nigeria," International Library Review 12:201-7 (1980).

5. Katherine Emerson, "National Reporting on Reference Transactions, 1976-78," RQ 16:199-207 (Spring 1977).

6. J. P. Wilkinson and W. Miller, "The Step Approach to Reference Services," RQ 17:293-300 (Summer 1978). 